\title{
En busca de una opinión pública moderna. La producción hemerográfica de los españoles exiliados en Inglaterra y su apropiación por la prensa mexicana, 1824-1827
}

José Luis Quezada Lara

El Colegio de México, México

jquezada@colmex.mx

María Eugenia Claps Arenas, En busca de una opinión pública moderna. La producción hemerográfica de los españoles exiliados en Inglaterra y su apropiación por la prensa mexicana, 1824-1827, México, Universidad de Ciencias y Artes de Chiapas-Centro de Estudios Superiores de México y Centroamérica/Juan Pablo Editor, 2020, pp. 223.

En busca de una opinión pública moderna, es el libro más reciente de María Eugenia Claps. Fue publicado por la Universidad de Ciencias y Artes de Chiapas y otras editoriales. Desde mi perspectiva, la obra se circunscribe en una línea tradicional de la historia de la prensa y la opinión pública. Esto obedece a dos razones. La primera, el punto de vista de la autora, pues pondera las producciones de la cultura impresa en las élites política y económicamente influyentes, con lo cual, sostiene, como tesis central, que la opinión pública comenzó a partir de 1800 y que ésta sólo se generaba en los periódicos. Dicha afirmación implicaría, como señala la autora, que sólo en la prensa el público podía leer, examinar, confrontar y configurar su opinión sobre temas de actualidad política y la formación de la nación (p. 21). La segunda, no obstante que la obra se publicó en 2020, ésta es producto de una tesis de maestría que se defendió en 1999, hecho que se refleja en sus enfoques y metodología. No

\section{(c) (i) (8)} 4.0 Internacional 
obstante, es verdad que alude a bibliografía producida durante la última década y hace referencia a trabajos inéditos, como el de Laura Martínez (2018).

La idea que anima al libro es el estudio de un aspecto interesante y poco conocido en la historia de la prensa en México. Es decir, la apropiación que los editores de periódicos de la ciudad de México hicieron de los contenidos y materiales hemerográficos producidos por los liberales españoles del Trienio Constitucional exiliados en Londres. Lo interesante es que esto implicó un proceso de descarte, edición, selección, uso y apropiación que los editores de la prensa nacional hicieron de los artículos o ensayos procedentes de esa nación con el fin de darlos a conocer a los lectores mexicanos y, con ello, promover determinadas agendas políticas, instruir al público con las novedades editoriales, y fomentar el debate público, sobre todo, en el Congreso y las instituciones de gobierno. Los cotidianos mexicanos que trabajó fueron El Sol, Águila Mexicana y Correo de la Federación Mexicana. A partir de estos, observó el modo en que sus editores retomaron materiales de las revistas $E l$ Español Constitucional, Ocios de Españoles Emigrados, Variedades o el Mensajero de Londres, entre otras, como las publicadas por el editor alemán Rudolph Ackermann para México y el resto de Hispanoamérica. En ese sentido, el estudio de esa actividad le permitió observar fenómenos interesantes en torno a la cultura impresa en México, entre 1824 y 1827. Por ejemplo, la división del pensamiento liberal español en el exilio inglés y la atención que la prensa mexicana puso a esos debates, la multiplicación de periódicos, folletos y hasta lectores en México, los vínculos y redes de la prensa mexicana con diversas agrupaciones masónicas, las discusiones de la feligresía católica en la prensa, el traslado, distribución y comercialización de publicaciones impresas en México y otras capitales de Hispanoamérica mediante la casa Ackermann, entre otros. Sin embargo, de estos y otros temas que son desarrollados por la autora, quiero concentrarme en dos puntos que me parecieron neurálgicos del libro.

En primer lugar, la importancia de Londres, capital donde residieron los exiliados liberales del Trienio Constitucional quienes trabajaron para empresas editoriales de Inglaterra, las cuales tenían interés de exportar sus ideas, abrirse camino, hacer negocios y llegar al mercado impreso en Hispanoamérica mediante la 
comercialización de publicaciones impresas. Para ello, contaron con la colaboración de sus gobiernos, con personajes bisagra como Vicente Rocafuerte, quien incluso apoyó económicamente a Ocios de Españoles Emigrados. Esta suerte de apertura comercial y vinculación entre México y Londres es notable si se considera que durante el mismo periodo Roma y España hicieron un frente común para desconocer y condenar los procesos de independencia en esos países (Cárdenas, 2018). En ese sentido, mediante el trabajo y coordinación editorial en ambos lados del Atlántico y sin las trabas del extinto sistema inquisitorial, los gobiernos independientes de Hispanoamérica se convirtieron en receptores de las teorías políticas, económicas, religiosas y sociales de los emigrados españoles en Inglaterra. Con lo cual, las ideas de José María Blanco White, los hermanos Villanueva, Canga Argüelles, entre otros, fueron difundidas en México sin mayores cortapisas por los periódicos locales arriba mencionados. Y, en el mismo sentido, estos autores vieron en Hispanoamérica el espacio idóneo para instruir a esas sociedades y tratar de evitar que los gobiernos americanos cometieran los mismos errores que en la España Absolutista. A ese respecto, un tema polémico fue el tratamiento que la prensa mexicana, ( $E l \mathrm{Sol}$, Águila Mexicana y Correo de la Federación Mexicana), dio a los artículos de los exiliados españoles en torno al patronato y la introducción de la tolerancia religiosa en México por el apoyo, deslinde y posicionamientos de los editores hacia esos temas.

En segundo lugar, me pareció sobresaliente el seguimiento de la autora al establecimiento de la casa editorial Ackermann en México, en 1825. Además de su trabajo editorial, este personaje apoyó a la insurgencia en Venezuela con prensas litográficas y, por otro lado, emprendió negocios en la zona minera mexicana de Tlalpujahua. Gracias al apoyo de Guadalupe Victoria y los editores mexicanos, la empresa de Ackermann pudo funcionar en el país con relativa seguridad vendiendo los libros y producciones de los exiliados españoles en Londres. Desde mi perspectiva, lo interesante de este emprendimiento fue la introducción de obras religiosas, por ejemplo, del deísmo inglés, como Teología natural..., de William Palley, cuya traducción corrió a cargo de Joaquín Lorenzo Villanueva. Además de este y otros impresos, sobresale la venta y distribución de biblias, al parecer, E-ISSN 2395-8464 https://doi.org/10.18234/secuencia.v0i0.1930 
producidas con el apoyo de la Sociedad Bíblica Británica y Extranjera, hecho que le ocasionó problemas con la feligresía católica en la prensa y, muy probablemente, con sus instituciones eclesiásticas (Mijangos, 2019, pp. 85-88). Quizá por ello, más el hecho de que los españoles exiliados dejaron de producir materiales impresos para Ackermann, el comerciante alemán cambió el giro de su negocio y se introdujo en la comercialización de objetos domésticos (pp. 124-128).

El libro tiene una conexión temática con un trabajo previo realizado por la autora. En aquel texto, María Eugenia Claps tuvo un primer acercamiento a la actividad intelectual de los refugiados en la capital inglesa mediante el estudio de Pablo de Mendíbil (Claps, 1994). En cuanto al reseñado, su investigación hemerográfica es muy sólida por los materiales revisados y por el conocimiento y reconstrucción de estos. En ese sentido, la obra contribuye al conocimiento del periodo a partir de la producción impresa y editorial en México, entre 1824 y 1827. Sin embargo, si tuviera que hacer una observación crítica hacia la misma, considero que se echa en falta la problematización conceptual de los enfoques en torno a la “opinión pública”. O, cuando menos, una explicación sobre la metodología que empleó y la desarrollada por otras historiografías en las últimas décadas. Baste recordar que los estudios recientes en torno al tema en Europa y América han privilegiado aspectos vinculados a los espacios y medios de comunicación, las fuentes y transformaciones de los aparatos de información, y la relación entre el Estado, él y lo público. Sobre todo, han puntualizado que la opinión pública puede rastrearse en sectores amplios de la población y que esta no sólo puede investigarse en la producción hemerográfica, sino también en los archivos y expedientes judiciales. Fuera de esta apreciación, considero que la investigación cumple con creces los objetivos que se planteó.

\section{Referencias}

Cárdenas, E. (2018). Roma: el descubrimiento de América. México: El Colegio de México. 
Claps Arenas, M. E. (1994). Pablo de Mendíbil y sus aportaciones a la historiografía mexicana. (Tesis de licenciatura), Universidad Nacional Autónoma de MéxicoFacultad de Filosofía y Letras, México.

Martínez, L. (2018). El Sol. 1823-1835. Un periódico político durante la primera república federal. (Tesis de doctorado inédita), Universidad Nacional Autónoma de México-Facultad de Filosofía y Letras, México.

Mijangos, P. (2019). La república católica y el difícil camino a la secularización del derecho mexicano. En J. R. Cossío, P. Mijangos, y E. Pani (coords.), Derecho y cambio social en la historia (pp. 79-101). México: El Colegio de México. 